\title{
Role of enteric bacteria in the pathogenesis of rheumatoid arthritis: evidence for antibodies to enterobacterial common antigens in rheumatoid sera and synovial fluids
}

Shigehisa Aoki, Kazuhiro Yoshikawa, Toru Yokoyama, Tsunemasa Nonogaki, Shinichi Iwasaki, Tadao Mitsui, Shigeo Niwa

\begin{abstract}
Objective-To study antibodies to Escherichia coli O:14, which expresses large amounts of enterobacterial common antigen (ECA), and their corresponding antigen molecules in serum and synovial fluid samples from patients with rheumatoid arthritis (RA).

Methods-Enzyme linked immunosorbent assay (ELISA) was used to measure antibodies to heat killed $E$ coli $0: 14$ in serum and synovial fluid samples from patients with RA and control subjects including healthy donors and patients with osteoarthritis. ELISA was also used to perform absorption analyses of antibodies to $E$ coli $0: 14$ with several enteric bacteria and their lipopolysaccharide (LPS). In addition, antigenic molecules reacting with $E$ coli $0: 14$ antibodies from patients with RA were examined using immunoblot analysis and $\mathbf{N}$-terminal amino acid analysis.
\end{abstract}

Results-Compared with control subjects, patients with RA showed significantly increased titres of antibodies against heat killed $E$ coli $0: 14$ in 33 of 83 serum samples $(39.8 \%)$ and 38 of 58 joint fluid samples $(65 \cdot 5 \%)$. Absorption analyses with enteric bacteria and their LPS resulted in the reduction of antibody titres to heat killed $E$ coli $0: 14$ in serum and synovial fluid samples from the $R A$ patients. In addition, immunoblot analysis of the samples from RA patients revealed not only a ladder-like banding pattern equivalent to ECA associated with LPS, but also two clear bands of bacterial outer membrane proteins of $35 \mathrm{kDa}$ (Omp A) and $38 \mathrm{kDa}$ (Omp C), having amino acid sequence homology with those of other Enterobacteriaceae.

Conclusion-These results suggest that some patients with $R A$ are sensitised to antigens common to Enterobacteriaceae, and this may prove relevant to the future development of immunotherapy for RA. Furthermore, this sensitisation to antigens found commonly in Enterobacteriaceae may have a key role in the pathogenesis of human RA similar to that described previously in our animal model.

(Ann Rheum Dis 1996; 55: 363-369)
Rheumatoid arthritis (RA) is a chronic systemic disease in which a non-suppurative inflammatory process affects diarthrodial joints, resulting in the destruction of multiple joints $;^{12}$ it is an immune mediated disease that is characterised by autoantibodies such as rheumatoid factors and type II collagen antibodies, and a clear genetic susceptibility. ${ }^{34}$ Rheumatoid factors are anti-IgG autoantibodies with specificity towards antigenic determinants in the $\mathrm{Fc}$ region of $\mathrm{IgG}$ and are detected in the majority of patients with RA. ${ }^{5}$ Autoantibodies to type II collagen are also frequently found within the joints of patients with RA. ${ }^{6}$ Recent observations suggest that the association between HLA-DR4 and, RA is strongest for patients with severe forms of the disease. ${ }^{7}$ However, the cause of RA remains unknown despite many years of intensive research.

In earlier studies, we reported the induction of RA-like arthritis in rabbits ${ }^{8}$ by hyperimmunisation with heat killed Escherichia coli $\mathrm{O}: 14$, which contains large amounts of the enterobacterial common antigen (ECA), ${ }^{9}$ and showed that a high proportion of the animals with induced arthritis also had high levels of antibodies to the $E$ coli antigen. ${ }^{10}$ The immunopathological similarities ${ }^{8} 10$ between the arthritic conditions induced in rabbits by hyperimmunisation with $E$ coli $\mathrm{O}: 14$ and those in human RA have stimulated a search for an enterobacterial aetiology of the latter condition.

In the present study, the presence of antibodies against heat killed $E$ coli $0: 14$ in serum and synovial fluid samples from patients with RA and control subjects including healthy donors and patients with osteoarthritis (OA) was examined by enzyme linked immunosorbent assay (ELISA) and absorption analyses of antibodies to $E$ coli O:14 were also carried out with enteric bacteria and their lipopolysaccharide (LPS) by ELISA. In addition, we studied the antigenic molecules reacting with anti- $E$ coli $\mathrm{O}: 14$ from patients with $\mathrm{RA}$ using immunoblot analysis and $\mathrm{N}$-terminal amino acid analysis.

\section{Patients and methods}

SUBJECTS AND SAMPLES

Serum samples from 83 patients with RA (mean age 55.5 years, range $28-85 ; 13$ men/70 women) and 62 healthy donors (mean age $47 \cdot 2$ 
years, range $28-67 ; 38 \mathrm{men} / 24$ women), and synovial fluid samples from 58 patients with RA (mean age 57.9 years, range $19-76 ; 19$ men/ 39 women) and 31 with OA (mean age $66 \cdot 2$ years, range $39-84 ; 10 \mathrm{men} / 21$ women) were randomly collected from the inpatient wards and outpatient clinics of our hospital and the related medical facilities of Aichi Medical University. All patients with RA fulfilled the 1987 revised criteria of the American College of Rheumatology (formerly the American Rheumatism Association) for the classification of RA. ${ }^{11}$ The median duration of their RA from the onset of symptoms was 78.9 months (range 2-372 months) in patients who provided serum samples and 106.8 months (range 2-384 months) in those who provided synovial fluid samples. The patients with RA were classified into two groups according to the duration of their disease: recent onset (RA for $\leq 1$ year) or established RA (RA for $>1$ year). Among the 83 who provided serum samples, 15 were in the recent onset group and 68 had established RA; among those giving synovial fluid samples, six had recent onset RA and 52 had established RA. The patients were also divided into groups based on four disease stages of RA according to the Steinbrocker grade of progression: ${ }^{12} 27$ patients were classified as stage I, 15 as stage II, three as stage III, and 38 as stage IV from serum samples; 11 were classified as stage I, seven as stage II, six as stage III, and 34 as stage IV from synovial fluid samples.

\section{BACTERIAL STRAINS AND PREPARATION OF ANTIGENS}

$E$ coli O:14 was kindly supplied by the Research Institute for Microbial Diseases, Osaka University, and Klebsiella pneumoniae (ATCC 13883), Proteus vulgaris (ATCC 13315), and $P$ mirabilis (ATCC 29906) were supplied by the National Institute of Health of Japan. These bacteria were prepared as described previously. ${ }^{10}$ Mycobacterium tuberculosis H37 RA was purchased from Difco Laboratories, Detroit, USA, and $M$ bovis (BCG vaccine) from Japan BCG Laboratory, Tokyo, Japan. Several LPSs purified by phenol extraction were kindly supplied by the Department of Bacteriology and Immunology, Aichi Medical University.

ENZYME LINKED IMMUNOSORBENT ASSAY

Titres of antibody to $E$ coli O:14 were determined by ELISA. ELISA plates (Maxisorp F96, Nunc, Roskilde, Denmark) were coated with $15 \mu \mathrm{g} / \mathrm{ml}$ of heat killed $E$ coli $\mathrm{O}: 14$. Nonspecific protein binding sites on the plates were blocked with phosphate buffered saline (PBS) containing $1 \%$ dried milk and $5 \%$ normal goat serum. Test serum and synovial fluid diluted to 1:20 were distributed into each of three wells and incubated overnight at $4^{\circ} \mathrm{C}$. Goat antihuman immunoglobulin (polyvalent) conjugated with horseradish peroxidase (HRP) (TAGO, Inc, Burlingame, USA) was added into each well, followed by incubation for one hour at $37^{\circ} \mathrm{C}$. After final washing, the amount of enzyme bound to the wells was assayed using $o$-phenylenediamine dihydrochloride solution. The reaction was stopped by adding $2 \mathrm{~mol} / \mathrm{l}$ sulphuric acid and the optical density (OD) at $492 \mathrm{~nm}$ was measured with an ELISA reader MPR-A4i (Tosoh Co, Tokyo, Japan).

ANTIBODY ABSORPTION ASSAY

For absorption assay of $E$ coli $\mathrm{O}: 14$ antibodies from patients with $\mathrm{RA}$, joint fluids were absorbed with $1600 \mu \mathrm{g} /$ well of several heat killed bacteria (whole organisms), and sera were absorbed with $200 \mu \mathrm{g} /$ well of whole heat killed $E$ coli $\mathrm{O}: 14$ and several extracted LPSs at room temperature for one hour. After the absorption process, the antibody titre of each sample was measured by ELISA methods as described above. The degree of absorption was estimated as the percentage inhibition $(100-[(100 \times$ OD value in the presence of bacteria or LPS) / OD value without bacteria or LPS]).

\section{IMMUNOBLOTTING ANALYSIS}

Heat killed $E$ coli O:14 antigens were separated by sodium dodecyl sulphate polyacrylamide gel electrophoresis through $12 \cdot 5 \%$ polyacrylamide gels, and transferred electrophoretically onto polyvinylidene difluoride (PVDF) membranes (Millipore Co, Bedford, USA), which were then soaked in blocking solution (PBS containing $1 \%$ dried milk and $5 \%$ normal goat serum) for six hours at room temperature. Serum and synovial fluid were diluted with blocking solution containing $0.05 \%$ Tween 20 and incubated with blocked antigen strips overnight at $4^{\circ} \mathrm{C}$ on a rocking platform. Bound antibodies were detected by incubation for one hour at room temperature with biotinylated goat antirabbit immunoglobulin (DAKO, Glostrup, Denmark) or biotinylated goat antihuman immunoglobulin (TAGO), followed by washing and incubation with avidin-biotinylated HRP complex (Vector Laboratories Inc, Burlingame, USA). After final washing, strips were visualised with 3,3'-diaminobenzidine tetrahydrochloride. For comparison, sera from rabbits with $E$ coli induced arthritis were also subjected to immunoblot analysis.

AMINO ACID SEQUENCING

Bacterial antigens were separated and transferred onto PVDF membranes as described above. The proteins on the membranes were stained with Coomassie brilliant blue R250 and the bands to be sequenced were cut out. Using the membrane strips, amino acid sequences were analysed by Applied Biosystems 477A protein sequencer (Foster, USA) and amino acid sequences of 14 residues and 12 residues, from purified $35 \mathrm{kDa}$ and $38 \mathrm{kDa}$ proteins of $E$ coli $\mathrm{O}: 14$, were obtained. Using the sequences obtained, searches for proteins with similar amino acid sequences were performed using Genetyx-MAC software (Software Development Co Ltd, Tokyo, Japan) with the National Biomedical Research Foundation Library data base (Release 41 ). 
STATISTICAL ANALYSIS

Differences in mean titre values in the RA and control groups were compared by MannWhitney $U$ test. Gender differences in antibody levels between observation groups and differences between the recent onset RA group and the established RA group were also analysed by the Mann-Whitney $U$ test. One factorial analysis of variance was used to analyse the significance of any difference in antibody levels among each of the four RA groups (stages I to IV). Differences between the results of the antibody absorption assays were evaluated by analysis of variance followed by the Scheffé post hoc test.

\section{Results}

MEASUREMENT OF ANTIBODIES BY ELISA

Each serum and synovial fluid sample was examined for antibodies to heat killed $E$ coli O:14 by ELISA. In the serum samples, mean (SEM) antibody levels (expressed as OD at $492 \mathrm{~nm}$ ) in 83 patients with RA and 62 healthy donors were $0.833(0.072)$ and $0.401(0.027)$, respectively ( $p<0.01$, Mann-Whitney $U$ test) (fig 1A). Similarly, in the synovial fluid samples, the difference in the mean values of antibody titres between the 58 patients with RA (0.593 (0.072)) and the 31 with OA (0.144 $(0.026)$ ) was also significant $(p<0.01)$ (fig 1B). There was no significant difference between men and women in antibody levels in serum and synovial fluid samples in any of the groups ( $p=0.55$ in RA sera, $p=0.09$ in control sera, $p=0.44$ in RA synovial fluids, $p=0.69$ in OA synovial fluids; Mann-Whitney $U$ test). Comparison of the antibody levels between the recent onset RA group and the established RA group in each serum and synovial fluid sample revealed no significant differences between those groups $(p=0.52$ in serum samples, $\mathrm{p}=0.94$ in synovial fluid samples; MannWhitney $U$ test). In addition, there was no significant difference in antibody levels among the four RA groups comprising stages I to IV of the disease in any of the samples $(p=0.14$
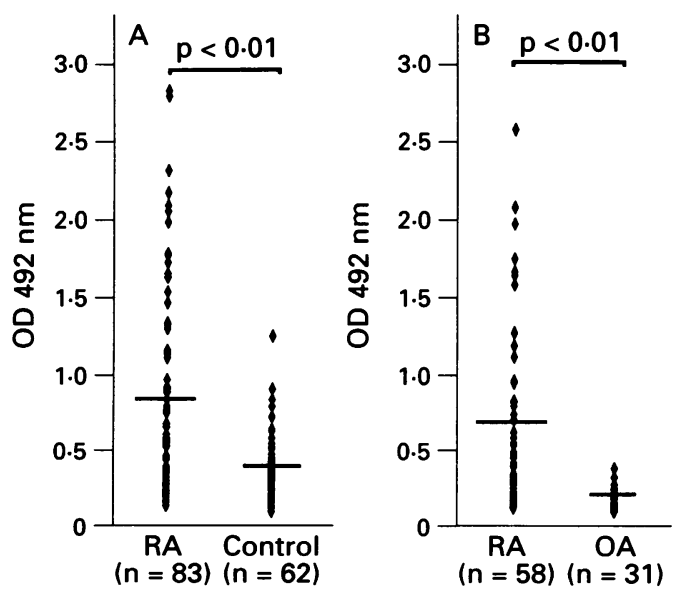

Figure 1 Comparison between levels of antibodies to $\mathrm{E}$ coli $O: 14$ in patients with rheumatoid arthritis $(R A)$ and control subjects. A: Sera from patients with $R A$ and healthy donors (Control); B: synovial fluids from patients with $R A$ and osteoarthritis $(O A)$. Horizontal bars indicate mean values. $O D=$ Optical density. in RA sera, $p=0.58$ in RA synovial fluids; analysis of variance).

Samples were regarded as positive when the OD was at least 2 standard deviations above the mean value in controls (healthy donors: $0.401+2 \times 0.215=0.831 ; \quad$ OA patients: $0.144+2 \times 0.067=0.278)$. Thirty three of 83 serum samples $(39.8 \%)$ and 38 of 58 joint fluid samples $(65.5 \%)$ showed positive reactivity with the $E$ coli O:14 antigens. Of the 83 serum and 58 synovial fluid samples collected randomly, 15 samples of paired sera and synovial fluids from the same patients with RA were included. Seven of these 15 patients $(46.7 \%)$ were positive in both serum and synovial fluid samples and five were negative in both samples; three were positive only in the synovial fluid samples.

\section{ABSORPTION ANALYSIS OF ANTIBODIES}

In ELISA absorption tests of $E$ coli $0: 14$ antibodies $(\mathrm{OD}=2 \cdot 475)$ in the synovial fluid from five RA patients with whole organisms of several heat killed bacteria, per cent inhibition with $E$ coli O:14, Klebsiella pneumoniae, Proteus vulgaris, $P$ mirabilis, Mycobacterium tuberculosis, and $M$ bovis were $86.4 \%, 49.5 \%, 70.5 \%$, $65 \cdot 3 \%, 10 \cdot 0 \%$, and $4 \cdot 5 \%$, respectively (fig $2 \mathrm{~A}$ ). Per cent inhibition values on absorption analysis with all heat killed enteric bacteria were much greater than those with the two mycobacteria $(p<0.01$, analysis of variance all groups; $p<0.01$, Scheffé post hoc test). Likewise, in the remaining joint fluids from four RA patients (OD values $2.021,1.912,1.594$, and 1.537), per cent inhibition values on absorption with enteric bacteria were also significantly greater than those with mycobacteria. When antibodies in sera from two patients with RA (patient No 90, OD = 1.843; patient No 99, $\mathrm{OD}=1.873$ ) were absorbed with whole $E$ coli O:14 or its extracted LPS, per cent inhibition of whole organism and LPS in RA patient No 90 were $96 \%$ and $86 \%$, and those of patient No 99 were $95 \%$ and $85 \%$ (fig $2 \mathrm{~B}$ ); the remaining sera from two RA patients showed an equivalent absorption pattern. In absorption analysis of an RA serum (OD $=2 \cdot 052)$ positive to $E$ coli $\mathrm{O}: 14$ with several LPS extracts, per cent inhibition of $E$ coli $\mathrm{O}: 14, E$ coli $\mathrm{O}: 8, E$ coli O:9, E coli O:111, and Salmonella typhi were $89.3 \%, 79.4 \%, 75.0 \%, 43.9 \%$, and $33.4 \%$, respectively (fig $2 \mathrm{C}$ ). Absorption analyses with enteric bacteria and their LPS thus resulted in the reduction of antibody titres to heat killed $E$ coli O:14 in the serum and synovial fluid samples from patients with RA.

\section{IMMUNOBLOT ANALYSIS}

Figure 3A shows an example of the immunoblot patterns against the released proteins of molecular weight of $35 \mathrm{kDa}$ and $38 \mathrm{kDa}$, and the ladder-like banding pattern of the sera from 10 arthritic rabbits and 33 RA patients who were positively immunoreactive against $E$ coli O:14 antigen by ELISA. These reaction patterns were found in all antisera from arthritic rabbits (fig 3A: lane 1). However, the 

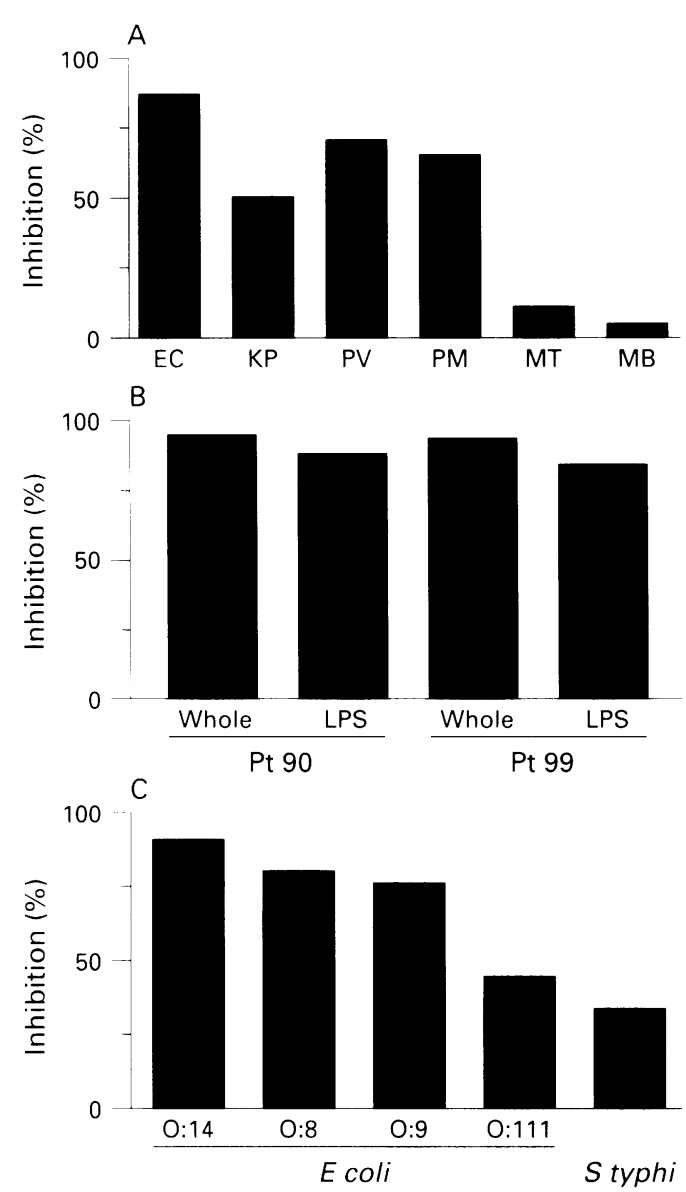

Figure 2 Absorption analysis (expressed as \% inhibition) of antibodies to $\mathrm{E}$ coli $O: 14$ from patients with rheumatoid arthritis $(R A)$, by enzyme linked immunosorbent assay. $A$ : Antibodies in joint fluid from a patient with $R A$ absorbed with several whole bacteria: $E C=\mathrm{E}$ coli $O: 14$; $K P=$ Klebsiella pneumoniae; $P V=$ Proteus vulgaris; $P M=\mathrm{P}$ mirabilis $; M T=$ Mycobacterium tuberculosis; $M B=M$ bovis. $B$ : Antibodies in sera from two patients with $R A$ (patient No 90, and patient No 99) absorbed with E coli O:14 (Whole) and its lipopolysaccharide (LPS) extracted. $C$ : Antibodies in the serum from a patient with $R A$ absorbed with LPS from four strains of $\mathrm{E}$ coli $(O: 14$, $O: 8, O: 9$, and $O: 111$ ) and Salmonella typhi (S typhi).

patterns in serum samples from RA patients were variable (fig 3A: lanes 3-5). We found strong immunoreactivity with the $35 \mathrm{kDa}$ protein in 20 serum samples $(60.6 \%)$ and with the $38 \mathrm{kDa}$ protein in 11 samples $(33.3 \%)$, and a ladder-like banding pattern in 14 samples $(42 \cdot 4 \%)$ of 33 patients with RA.

Paired serum and synovial fluid samples from two RA patients with antibodies to $E$ coli O:14 were also studied by immunoblotting. Identical staining of the $35 \mathrm{kDa}$ protein and a ladder-like pattern were found in both the serum and the synovial fluid samples (fig 3B). In addition, $41 \mathrm{kDa}$ and $63 \mathrm{kDa}$ protein bands that were not observed in the serum from arthritic rabbits (fig 3A, lane 1) were seen occasionally in paired samples from patients with RA (fig 3B).

\section{AMINO ACID SEQUENCE ANALYSIS}

The N-terminal amino acid sequence of the 35 $\mathrm{kDa}$ protein detected by immunoblot analysis showed significant homology with those of OmpA outer membrane proteins from $E$ coli K-12, Shigella dysenteriae, Salmonella typhi- murium, and Enterobacter aerogenes (fig 4A). The known 346 amino acid residues of the OmpA protein from $E$ coli $\mathrm{K}-12^{13}$ indicated 97\% overlap with the Shigella OmpA sequence, ${ }^{1+}$ $92 \%$ overlap with Salmonella OmpA sequence, ${ }^{15}$ and $85 \%$ overlap with the Enterobacter OmpA sequence. ${ }^{16}$ Furthermore, the N-terminal amino acid sequence of the $38 \mathrm{kDa}$ protein detected by Western blotting showed significant similarity to the OmpC protein of $E$ coli $\mathrm{K}-12$ and Salmonella typhi (fig 4B). The known 367 residues of $\mathrm{OmpC}$ from $E$ coli $\mathrm{K}-12^{17}$ indicated $78 \%$ overlap with the amino acid sequence of OmpC of Salmonella typhi. ${ }^{18}$

\section{Discussion}

This study has demonstrated that patients with RA showed significantly increased titres of antibody against heat killed $E$ coli $\mathrm{O}: 14$ in 33 of 83 serum samples $(39.8 \%)$ and 38 of 58 synovial fluid samples $(65.5 \%)$ compared with controls (healthy donors and OA patients) on ELISA, and the results of absorption analysis of the $E$ coli $\mathrm{O}: 14$ antibodies suggested the presence of antibodies against antigens common among Enterobacteriaceae, including ECA associated with LPS in patients with RA.

The ECA of $E$ coli O:14, first described as a cross reacting species by Kunin et al, ${ }^{9}$ is common to most members of the family Enterobacteriaceae. We first demonstrated the presence of ECA in the cell walls of $E$ coli, Klebsiella, and Proteus by the indirect immunofluorescent method using $E$ coli O:14 antiserum. ${ }^{19}$ Preparations of $E$ coli O:14 LPS contain ECA in large amounts or in an immunogenic form. ${ }^{20} \mathrm{ECA}$ in immunoblots shows a ladder-like pattern of at least 20 bands, ${ }^{21}$ indicating a heterogeneity of chain lengths similar to that demonstrated for smooth LPS. ${ }^{2-}$ The ladder-like banding pattern seen on immunoblot analysis of RA samples tested may therefore have been attributable to reaction with antibodies to ECA associated with LPS. In contrast, the $35 \mathrm{kDa}$ and $38 \mathrm{kDa}$ proteins observed on Western blot analysis of RA samples were identified as OmpA and OmpC proteins by $\mathrm{N}$-terminal amino acid analysis, and it has also been shown that both the OmpA and OmpC proteins possessed amino acid sequence similarity among the Enterobacteriaceae. OmpA is one of the most abundant proteins of the outer membrane of the $E$ coli cell envelope, ${ }^{23}$ and OmpC is known as one of the peptidoglycan associated proteins that form hydrophilic channels across the outer membrane. ${ }^{17}$ Accordingly, antibodies against each of the OmpA and OmpC proteins showing cross reactivity between the outer membrane proteins of Enterobacteriaceae could be expected to be detected more consistently in serum and synovial fluid samples from patients with RA.

In this study, antibodies against $E$ coli $\mathrm{O}: 14$ antigens, including the ECA associated with LPS, OmpA, and OmpC, were detected frequently in serum and synovial fluid samples collected randomly from RA patients. Although women are affected with RA more frequently than men, and women are more 
A

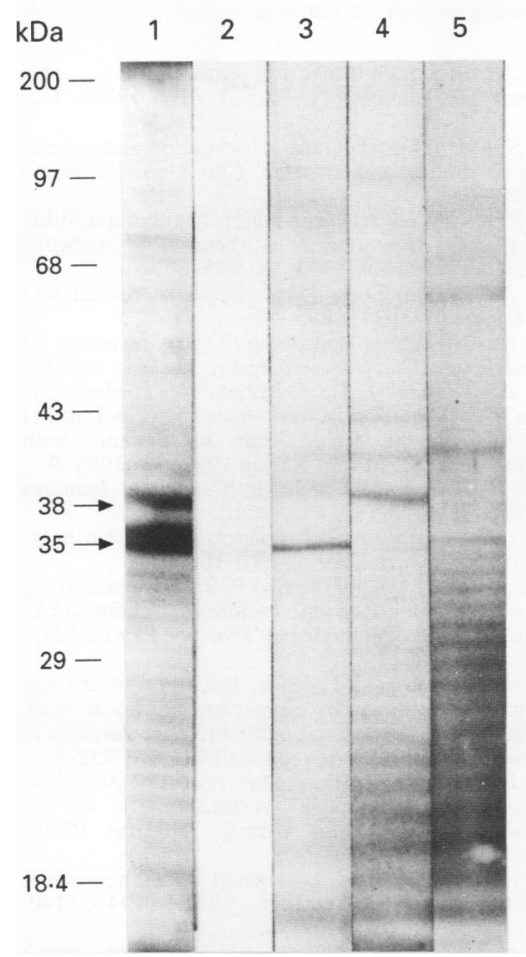

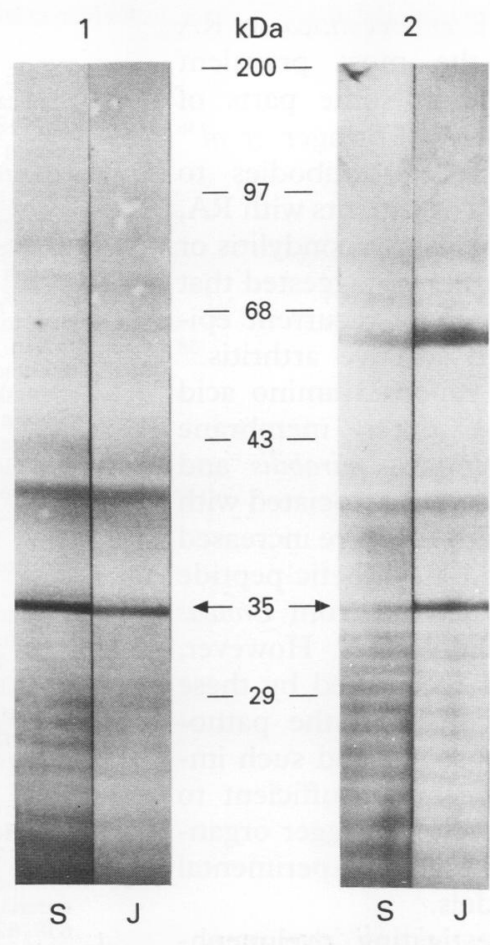

Figure 3 Immunoblotting analyses of rheumatoid arthritis $(R A)$ serum and joint fluid responses to $\mathrm{E}$ coli $O: 14$ antigens. A: LANE $1=$ serum from rabbits with chronic polyarthritis induced by hyperimmunisation with $\mathrm{E}$ coli $O: 14 ;$ LANE $2=$ serum from nonimmunised rabbit; LANES 3-5 = sera from patients with $R A$. B: Paired serum (S) and joint

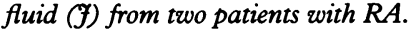

likely to suffer from urinary tract infections than men, no significant differences between men and women were found in either serum or synovial fluid samples from patients with RA. There were also no significant differences between the recent onset RA group and the established RA group, or among each of the four RA groups (stages I to IV). In addition, the positive rate in paired serum and synovial fluid samples from patients with $\mathrm{RA}$ was $46.7 \%$, and antibodies to common antigens in Enterobacteriaceae could be detected consistently in serum and synovial fluid samples from patients with RA in all of the groups tested.

A

$35 \mathrm{kDa}$ protein (E coli 0:14)

E coli K-12

Shigella dysenteriae

Salmonella typhimurium

Enterobacter aerogenes

B

$38 \mathrm{kDa}$ protein (E coli O:14)

: AEVYNKDGNKLD

E coli K-12

Salmonella typhi . . . . . . .

Figure 4 Comparison of the $N$-terminal amino acid sequence of $35 \mathrm{kDa}(\boldsymbol{A})$ and $38 \mathrm{kDa}(\boldsymbol{B})$ proteins of $\mathrm{E}$ coli $O: 14$ with the sequences of $O m p A(\boldsymbol{A})$ and $O m p C(\boldsymbol{B})$ proteins of other bacteria.
More data will be needed to clarify the clinical implications of these findings.

With the exception of the ladder-like banding pattern and two bands of $35 \mathrm{kDa}$ and $38 \mathrm{kDa}$ proteins seen on Western blot analysis, each band of $41 \mathrm{kDa}$ and $63 \mathrm{kDa}$ proteins was also detected occasionally in both the serum and the synovial fluid samples from patients with RA. These proteins correspond to heat shock proteins of $E$ coli $\mathrm{dnaJ}^{24}$ and groEL, ${ }^{25}$ respectively. $E$ coli groEL belongs to the heat shock protein 60 family, together with the structurally related myocobacterial heat shock protein 65 showing cross reactivity with many other bacteria.$^{26}$ The data regarding heat shock protein 60 are conflicting. Tsoulfa et $a l^{27}$ reported that the serum antibody levels against mycobacterial $65 \mathrm{kDa}$ heat shock protein by ELISA were significantly greater in patients with RA than in controls. In contrast, Lai et $a l^{28}$ reported that patients with RA did not show any characteristic increase in mycobacterial 65 $\mathrm{kDa}$ heat shock protein specific antibodies compared with healthy individuals. Nevertheless, Evans et $a l^{29}$ demonstrated the human groEL stress protein homologue in rheumatoid synovium sections, using a monoclonal antibody against the $65 \mathrm{kDa}$ heat shock protein of mycobacteria. In contrast, Albani et $a^{24}$ reported that there was amino acid sequence homology (QKRAA) between the third hypervariable region of HLA-DRB1 0401 having a bearing on susceptibility to RA and $E$ coli dnaJ, and that antibodies raised to dnaJ bound to cells bearing HLA-DR4 and -Dw4, suggesting autoimmunity mediated by antibodies. More recently, Albani et $a l^{30}$ reported that synovial fluid mononuclear cells of patients with early RA had strong immune responses to the QKRAA sequence on the $E$ coli heat shock protein dnaJ, and considered that the activated $T$ cells might cross react with autologous dnaJ heat shock proteins that were expressed at synovial sites of inflammation. Thus heat shock proteins have been the focus of considerable attention in recent years with regard to the pathogenesis of RA. However, in the present study, bands corresponding to dnaJ and groEL by Western blotting were not consistently detectable in patients with RA.

The hypothesis that RA may be triggered by enterobacterial antigens in genetically susceptible individuals has often been proposed, ${ }^{31-33}$ and several organisms have been implicated, including Clostridium perfringens, ${ }^{34}$ Yersinia, ${ }^{35}$ and Proteus. ${ }^{36} \mathrm{Cl}$ perfringens was first implicated in the aetiology of RA in 1968, when Olhagen and Månsson reported abnormal intestinal flora, characterised by increased numbers of $\mathrm{Cl}$ perfringens in faecal samples from patients with $\mathrm{RA}$ and increased antibody titres against $\mathrm{Cl}$ perfringens alpha toxin. ${ }^{32}$ In pigs fed a diet high in fish protein, clostridial overgrowth was also induced and concomitant development of RAlike arthritis was observed. ${ }^{37}$ Recently, Gripenberg ${ }^{35}$ reported that antibodies against Yersinia enterocolitica LPS could be detected not only in yersinia arthritis but also in $16 \%$ of patients with RA, using the ELISA technique. However, epidemiological findings ${ }^{1}$ indicating 
a worldwide distribution of RA do not support an aetiological role for $Y$ enterocolitica in RA because yersiniosis is the most prevalent enteric infectious disease in some parts of Scandinavia. More recently, Ebringer et $a l^{36}$ reported increased levels of antibodies to Proteus mirabilis in the sera of patients with RA, but not in those with ankylosing spondylitis or control subjects. These authors suggested that RA might be the end stage of recurrent episodes of Proteus induced reactive arthritis. ${ }^{38}$ Furthermore, they have reported amino acid homology between the outer membrane haemolysin protein of Proteus mirabilis and HLA-DR1 and -DR4 subtypes associated with $\mathrm{RA},{ }^{39}$ and that patients with RA have increased titres of antibodies against a synthetic peptide common to HLA-DR4 derived from Proteus mirabilis membrane haemolysin. ${ }^{40}$ However, how the Proteus antigens recognised by these antibodies might be involved in the pathogenesis of RA remains obscure, and such immunochemical data alone are insufficient to prove conclusively the role of a trigger organism in RA because of the lack of experimental support from animal models.

Previously, while investigating pyelonephritis caused by Enterobacteriaceae, ${ }^{41}$ we observed a chronic polyarthritis ${ }^{8}$ in rabbits that was induced by hyperimmunisation with $E$ coli O:14. This animal model closely resembled human RA, not only pathohistologically, but also serologically and immunohistologically. Further study ${ }^{10}$ revealed that a large proportion of the animals with induced arthritis had high levels of antibodies to the $E$ coli O:14 antigen, and we suggested that a genetic influence was important in the development of RA-like illness. Although, on the basis of the immunohistological localisation of $E$ coli antigens in the joint tissue of arthritic rabbits, ${ }^{8}$ we have considered the possibility that $E$ coli O:14 LPS may have a direct role in the development of arthritis, ${ }^{10}$ Noyori et al ${ }^{42}$ reported experimental induction of arthritis in rats immunised with $E$ coli O:14 LPS and suggested that local stimulation of production of interleukin-1 might play an important part in the induction of experimental arthritis. In the light of these experimental findings, we tested for antibodies against heat killed $E$ coli $0: 14$ in serum and synovial fluid samples from patients with RA and have presented new evidence in this study that, in addition to our experimental animal model resembling $R A$, some patients with $R A$ were sensitised to antigens common to Enterobacteriaceae, such as the ECA associated with LPS, OmpA, and OmpC.

In conclusion, we consider it possible that, in patients with RA, intestinal flora may provide a continuing cross reactive stimulus after the initial triggering infection has passed. If sensitisation to common antigens in Enterobacteriaceae is confirmed in patients with RA, hyposensitisation with bacterial vaccines including OmpA and OmpC should be given, in addition to the usual methods of symptomatic treatment.

This work was supported in part by the Research Grant for the Intractable Diseases from the Ministry of Health and Welfare,
Japan. The authors wish to thank Drs T Okumura and C Kato for help in collecting the clinical samples.

1 Harris E D Jr. Rheumatoid arthritis. Pathophysiology and implications for therapy. $N$ Engl $f$ Med 1990; 322: 1277-89.

2 Firestein GS. Mechanisms of tissue destruction and cellular activation in rheumatoid arthritis. Curr Opin Rheumatol 1992; 4: 348-54

3 Gregersen P K. T-cell receptor-major histocompatibility complex genetic interactions in rheumatoid arthritis. Rheum Dis Clin North Am 1992; 18: 793-807.

4 Sewell K L, Trentham D E. Pathogenesis of rheumatoid arthritis. Lancet 1993; 341: 283-90.

5 Johnson $\mathrm{P} M$. Molecular nature and cross-reactions of rheumatoid factor. Clin Immunol Allergy 1981; 1: 103-15. Tarkowski A, Klareskog L, Carlsten H, Herberts P Koopman W J. Secretion of antibodies to types I and II collagen by synovial tissue cells in patients with rheumatoid arthritis. Arthritis Rheum 1989; 32: 1087-92.

7 Wordsworth P. Rheumatoid arthritis. Curr Opin Immunol 1992; 4: 766-9.

8 Aoki S, Ikuta K, Aoyama G. Induction of chronic polyarthritis in rabbits. Nature 1972; 237: 168-9.

9 Kunin C M, Beard M V, Halmagyi N E. Evidence for a common hapten associated with endotoxin fractions of $\mathrm{E}$. coli and other Enterobacteriaceae. Proc Soc Exp Biol Med 1962; 111: 160-6.

10 Aoki S, Ikuta K, Nonogaki T, Ito Y. Induction of chronic polyarthritis in rabbits by hyperimmunization with Escherichia coli. I. Pathologic and serologic features in two breeds of rabbits. Arthritis Rheum 1985; 28: 522-8.

11 Arnett F C, Edworthy S M, Bloch D A, et al. The American Rheumatism Association 1987 revised criteria for the classification of rheumatoid arthritis. Arthritis Rheum 1988; 31: 315-24.

12 Steinbrocker O, Traeger C H, Batterman R C. Therapeutic criteria in rheumatoid arthritis. $\mathscr{f} A M A 1949 ; 140$ 659-62.

13 Beck E, Bremer E. Nucleotide sequence of the gene ompA coding the outer membrane protein II of Escherichia coli K-12. Nucleic Acids Res 1980; 8: 3011-24.

14 Braun G, Cole $S T$. The nucleotide sequence coding for major outer membrane protein OmpA of Shigella major outer membrane protein OmpA of
dysenteriae. Nucleic Acids Res 1982; 10: 2367-78.

15 Freudl $R$, Cole $S T$. Cloning and molecular characterization of the ompA gene from Salmonella typhimurium. Eur $\mathcal{F}$ Biochem 1983; 134: 497-502.

16 Braun G, Cole S T. Molecular characterization of the gene coding for major outer membrane protein OmpA from Enterobacter aerogenes. Eur $\mathcal{F}$ Biochem 1983; 137: 495-500.

17 Mizuno T, Chou M-Y, Inouye M. A comparative study on the genes for three porins of the Escherichia coli outer membrane. DNA sequence of the osmoregulated ompC gene. $\mathcal{F}$ Biol Chem 1983; 258: 6932-40.

18 Venegas A, Gómez I, Zaror I, Yudelevich A. The nucleotide sequence of the Salmonella typhi ompC porin gene. Nucleic Acids Res 1988; 16: 7721.

19 Aoki S, Merkel M, McCabe W R. Immuofluorescent demonstration of the common enterobacterial antigen. Proc Soc Exp Biol Med 1966; 121: 230-4.

20 Hammarström S, Carlsson H E, Perlmann P, Svensson S. Immunochemistry of the common antigen of Enterobacteriaceae (Kunin). Relation to lipopolysaccharide cor structure. $₹$ Exp Med 1971; 134: 565-76.

21 Kuhn H-M, Basu S, Mayer H. Comparison of enterobacterial common antigen from different species by serological techniques. Eur $₹$ Biochem 1987; 162: 69-74.

22 Palva E T, Mäkelä P H. Lipopolysaccharide heterogeneity in Salmonella typhimurium analyzed by sodium dodecyl sulfate/ polyacrylamide gel electrophoresis. Eur F Biochem 1980; 107: 137-43.

23 Chen R, Schmidmayr W, Krämer C, Chen-Schmeisser U, Henning U. Primary structure of major outer membrane protein II (ompA protein) of Escherichia coli K-12. Proc Natl Acad Sci USA 1980; 77: 4592-6.

24 Albani S, Tuckwell J E, Esparza L, Carson D A, Roudier J. The susceptibility sequence to rheumatoid arthritis is a cross-reactive $B$ cell epitope shared by the Escherichia coli heat shock protein dnaJ and the histocompatibility leukocyte antigen DRB10401 molecule. F Clin Invest 1992; 89: 327-31

25 Neidhardt F C, VanBogelen R A, Vaughn V. The genetics and regulation of heat-shock proteins. Ann Rev Genet 1984; 18: 295-329.

26 Young D B, Ivanyi J, Cox J H, Lamb J R. The $65 \mathrm{kDa}$ antigen of mycobacteria - a common bacterial protein? Immunol Today 1987; 8: 215-9.

27 Tsoulfa G, Rook G A W, Van-Embden J D A, et al. Raised serum IgG and IgA antibodies to mycobacterial antigens in rheumatoid arthritis. Ann Rheum Dis 1989; 48: in rheum.

28 Lai N S, Lan J L, Yu C L, Lin R H. Antibody to Mycobacterium tuberculosis $65 \mathrm{kDa}$ heat shock protein in patients with rheumatoid arthritis-A survey of antigen-specific antibody isotypes and subclasses in an endemic area of previous

29 Evans D J, Norton P, Ivanyi J. Distribution in tissue sections of the human groEL stress-protein homologue. APMIS of the human gro:

30 Albani S, Keystone E C, Nelson J L, et al. Positive selection in autoimmunity: abnormal immune responses to a 
bacterial dnaJ antigenic determinant in patients with early rheumatoid arthritis. Nature Medicine 1995; 1: 448-52.

31 Bennett J C. The infectious etiology of rheumatoid arthritis. New considerations. Arthritis Rheum 1978; 21: 531-8.

32 Midtvedt T. Intestinal bacteria and rheumatic disease. 31. Scand $\mathcal{F}$ Rheumatol 1978; 64(suppl): 49-54.

33 Hazenberg M P, Klasen I S, Kool J, Ruseler-van Embden J G H, Severijnen A J. Are intestinal bacteria involved in the etiology of rheumatoid arthritis? APMIS 1992; 100: 1-9.

34 Olhagen B, Månsson I. Intestinal Clostridium perfringens in rheumatoid arthritis and other collagen diseases. Acta Med Scand 1968; 184: 395-402.

35 Gripenberg $M$. Common serological features in rheumatoid arthritis and yersinia arthritis. Demonstration of rheumatoid factors and antibodies against ssDNA and Yersinia enterocolitica lipopolysaccharide by ELISA. Scand $\mathcal{f}$ Rheumatol 1981; 10: 85-91.

36 Ebringer A, Ptaszynska T, Corbett $M$, et al. Antibodies to proteus in rheumatoid arthritis. Lancet 1985; ii: 305-7.

37 proteus in rheumatoid arthritis. Lancet 1985, is. Arthritis in pigs induced by dietary factors. Microbiologic, clinical and histologic studies. Clin Exp Immunol 1971; 9: 677-93.

38 Ebringer A, Cox N L, Abuljadayel I, et al. Klebsiella antibodies in ankylosing spondylitis and Proteus antibodies in rheumatoid arthritis. Br $\mathcal{f}$ Rheumatol 1988; 27(suppl II): $72-85$.

39 Ebringer A, Cunningham P, Ahmadi K, Wrigglesworth J, Hosseini R, Wilson C. Sequence similarity between HLADR1 and DR4 subtypes associated with rheumatoid arthritis and proteus/ serratia membrane haemolysins. Ann Rheum Dis 1992; 51: 1245-6.

40 Wilson C, Ebringer A, Ahmadi K, et al. Shared amino acid sequences between major histocompatibility complex class II glycoproteins, type XI collagen and Proteus mirabilis in rheumatoid arthritis. Ann Rheum Dis 1995; 54: 216-20.

41 Aoki S, Imamura S, Aoki M, McCade W R. Abacterial and bacterial pyelonephritis. Immunofluorescent localization of bacterial antigen. $N$ Engl f Med 1969; 281: 1375-82.

42 Noyori K, Okamoto R, Takagi T, Hyodo A, Suzuki K, Koshino T. Experimental induction of arthritis in rats immunized with Escherichia coli O:14 lipopolyimmunized with Escherichia coli $0: 1$ 